\title{
Modulating the bicoid gradient in space and time
}

\author{
Xiaoli Cai ${ }^{1}$, Inge Rondeel ${ }^{1,2}$ and Stefan Baumgartner ${ }^{1,3^{*}}$ (1)
}

\begin{abstract}
Background: The formation of the Bicoid (Bcd) gradient in the early Drosophila is one of the most fascinating observations in biology and serves as a paradigm for gradient formation, yet its mechanism is still not fully understood. Two distinct models were proposed in the past, the SDD and the ARTS model.

Results: We define novel cis- and trans-acting factors that are indispensable for gradient formation. The first one is the poly A tail length of the bcd mRNA where we demonstrate that it changes not only in time, but also in space. We show that posterior bcd mRNAs possess a longer poly tail than anterior ones and this elongation is likely mediated by wispy (wisp), a poly A polymerase. Consequently, modulating the activity of Wisp results in changes of the Bcd gradient, in controlling downstream targets such as the gap and pair-rule genes, and also in influencing the cuticular pattern. Attempts to modulate the Bcd gradient by subjecting the egg to an extra nuclear cycle, i.e. a $15^{\text {th }}$ nuclear cycle by means of the maternal haploid $(\mathrm{mh})$ mutation showed no effect, neither on the appearance of the gradient nor on the control of downstream target. This suggests that the segmental anlagen are determined during the first 14 nuclear cycles. Finally, we identify the Cyclin B (CycB) gene as a trans-acting factor that modulates the movement of Bcd such that Bcd movement is allowed to move through the interior of the egg.

Conclusions: Our analysis demonstrates that Bcd gradient formation is far more complex than previously thought requiring a revision of the models of how the gradient is formed.
\end{abstract}

\section{Introduction}

The formation of the Bicoid (Bcd) gradient in Drosophila is one of the most fascinating observations in biology that has intrigued scientists for many decades [1]. Originally discovered as a Drosophila mutant that affects anterior patterning of the early egg [2], the remarkable Bcd protein gradient became the hallmark that served as paradigm for gradient formation in science for almost three decades [3]. To explain the occurrence of the gradient, a model was first proposed in 1988, the SDD model [1, 3-5]. The 3 letters SDD stand for synthesis, diffusion, degradation. The SDD model proposed that the $b c d$

\footnotetext{
*Correspondence: Stefan.Baumgartner@med.lu.se

${ }^{1}$ Departmentof Experimental Medical Sciences, Lund University, BMC D10, 22184 Lund, Sweden

Full list of author information is available at the end of the article
}

mRNA, held at the tip upon fertilization and later stages of the embryo, would serve as the source for the translation of the Bcd protein. Bcd protein would then diffuse uniformly through the entire embryo to form the gradient, followed by uniform degradation. In 2007, the first doubts on the validity of the model appeared, because the diffusion properties of Bcd were found to be too low to account for establishing a steady-state gradient in the short period of $2 \mathrm{~h}$ during egg development [6]. The ARTS model [1, 7] was proposed in 2009 to solve the apparent difficulty of the SDD model in explaining the fast establishment of the gradient. ARTS stands for active RNA transport synthesis. The model was based on earlier observations [8] that the $b c d$ mRNA itself formed a gradient. To account for the rapid gradient establishment, a model was proposed that involved active transport of the $b c d$ mRNA along microtubules (MTs) at the cortex original author(s) and the source, provide a link to the Creative Commons licence, and indicate if changes were made. The images or other third party material in this article are included in the article's Creative Commons licence, unless indicated otherwise in a credit line to the material. If material is not included in the article's Creative Commons licence and your intended use is not permitted by statutory regulation or exceeds the permitted use, you will need to obtain permission directly from the copyright holder. To view a copy of this licence, visit http://creativecommons.org/licenses/by/4.0/. The Creative Commons Public Domain Dedication waiver (http://creativeco mmons.org/publicdomain/zero/1.0/) applies to the data made available in this article, unless otherwise stated in a credit line to the data. 
of the embryo [7]. Since the transport of $b c d$ mRNA was shown using in vivo imaging $[9,10]$ to occur in the oocyte at a speed range of $0.36-2.15 \mu \mathrm{m} / \mathrm{sec}$, it was conceivable to assume that the egg used the same machinery to transport the mRNA away from the anterior tip to the posterior of the egg. The ARTS model necessitated the existence of a cortical MT network to serve for the transport [7]. An important facet of the ARTS model was that the observed speed of the active transport was fast enough to explain the establishment of the gradient in the given time. It took some time until a report on the proposed microtubular network at the cortex was published [11]. The transient network built up only for a short time during metaphase and early anaphase of each nuclear cycle and after that was immediately degraded again. Henc, it was visible for approximately 2 min during an early nuclear cycle lasting about 10 min [12]. Fahmy $\mathrm{K}$, et al. [11] also identified a MT-minus-end motor protein, Ncd as a player of this transport machinery and essential for the posteriorwards transport of the $b c d$ mRNA. In a following report, [13] revealed that the Bcd protein consistently moved along the outermost cortex and never entered the interior of the egg, thus defining the interior yolk as a non-permissive territory for Bcd movement. If drugs compromising the major constituent of the egg's cytoarchitecture, the microtubules (MTs) or actin were administered, the behavior of the movement of the Bcd protein changed significantly [13]. Upon drug administration, the interior of the egg became permissive, and Bcd moved to the posterior in a broad front, thus conforming to the SDD model [3]. While disrupting microtubules had a significant effect on Bcd movement, compromising actin had an effect on Bcd stability, but was not strongly involved in Bcd movement [13]. Consistent with this definition of the cortex as the major compartment in the early Drosophila egg, a recent study on the diffusion of proteins revealed that test proteins always migrated along the cortex, but never entered the yolk [14]. Of note, hints as to the compartmentalization of the early Drosophila egg already came from early studies using simple microscopic observations [12]. However, the analysis of the composition and biochemical properties of the inner yolk had been largely neglected in the past, primarily due to technical challenges during the analyses of the optically-dense material which led to sparse information of the interior structure of the early egg [15-18]. Only during recent advances has the use of fluorescent techniques allowed to shed some light into the activities of the inner part of the egg [19].

Based on the fact that early nuclei were never located at the cortex, little information was available in regard to whether or not a microtubular organizing center (MTOC) would exist at the cortex to initiate growth and destruction of the short-lived MT-network. Hints to the existence of a Golgi-based acentriolar microtubule organizing center (aMTOC) came first from vertebrate studies showing that structures at the trans-Golgi could serve as a starting point for MT nucleation [20]. Only very recently has [21] shown that Golgi structures do have an impact on $b c d$ mRNA localization in the oocyte and the early Drosophila embryo, where they depended on components of the trans-Golgi compartment. In terms of the localization of Golgi structures in the early Drosophila egg, some were shown to be present at the cortex [21-23], but we are far from understanding how the cortical Golgi apparatus of the early Drosophila embryo is organized.

Additional theories of nucleating MTs at the cortex were recently proposed in the context of lipid droplets (LD) and yolk granules (YG) and the possibility that LD-associated proteins can exert control on MT nucleation from centrosomes [24]. One of these proteins associated with YGs was shown to be Mauve/LYST. Since YGs are strongly enriched in the cortical layer of the early Drosophila embryo, it was conceivable that MTs can also be nucleated from yolk granules and that these structures together with Mauve/LYST constitute another aMTOC at the cortex.

In the past, a number of factors affecting the activity of $b c d$, either at the mRNA or protein level were detected. Each have a distinct mode of interaction with $b c d$. At the mRNA level, the most prominent ones were the RNA-binding proteins Staufen [25], the poly A polymerase Wispy [26], the pseudonuclease Exuperantia [27], the RNA-binding proteins Pumillio and Nanos [28], the ESCRT-II complex member VPS36 [29] and and the RNA-binding protein/motor protein Dyneinmediator Eglitarian [30]. Of note, most of these interactions are based on binding of these proteins to the long 3'UTR of the $b c d$ mRNA. This long stretch also harbors several distinct intrinsic functions such as the dimerization domain $[25,31]$, a mRNA stability region [32] and dependence of the translation efficiency of the mRNA, dependent on the length of the poly A tail $[33,34]$.

On the protein side, the most prominent targets of Bcd are the mRNA of the transcription factor Caudal that controls posterior development $[35,36]$, as well as the many transcription factors that control segmentation including the gap genes, pair-rule genes and segment polarity genes (reviewed by $[37,38]$. Notably, Bcd also interacts with many other proteins and may not necessarily be involved in DNA-binding-mediated gene regulation [39]. Indirect evidence for Bcd being trapped in an actin network came from Bcd-movement studies showing strong assembly of Bcd in energids, an actin-rich zone 
$[13,40]$. Whether this co-localization is due to direct binding to actin or just loose assembly in a protective actin shell to prevent degradation is currently unclear.

In this paper, we sought to define additional factors involved in shaping the $b c d$ gradient. Through a series of novel approaches to analyze $b c d$ gradient formation, we provide evidence that Bcd gradient formation is far more complex than previously thought and demonstrate that the gradient can be modulated in space and time.

\section{Results}

\section{Wispy and PAP2, two poly A polymerases acting on bcd mRNA localization}

In search of factors that can modulate the formation of the Bcd gradient, we stumbled over the PAP2 and wispy (wisp) genes, the poly A polymerase orthologues in Drosophila, respectively [41-43]. PAP2 is the canonical poly A polymerase and is mainly required for poly A tail synthesis of the immature mRNA in the nucleus. Wisp, on the other hand, belongs to the family of atypical poly A polymerases of the GLD-2 family which was first identified in C. elegans [44] and subsequently later in most phyla $[45,46]$. All GLD-2 poly A polymerase were shown to exert more specific functions than PAP2 and thus can be considered specialized poly A polymerases [46].

We decided to investigate the role of both poly A polymerases for $b c d$ gradient formation, prompted by reports that both genes are involved in shaping the length of the poly A tail of the $b c d$ mRNA during development [41, 43]. We first focused on the effect of poly A polymerases on $b c d$ mRNA localization during oogenesis and early embryogenesis (Fig. 1). While in PAP2 mutants, by using a strong $h r g^{P A P 12}$ allele [41] showed the $b c d$ mRNA localization pattern was indistinguishable from that of wild-type during oogenesis and embryogenesis (data not shown), oocytes from wisp ${ }^{K G / D f}$ mutant mothers, a null mutant, showed insufficient transport of the $b c d$ mRNA to the anterior pole (Fig. 1A). Instead, the mRNA became localized laterally. Subsequently, in later staged oocytes, this lateral localization remained accentuated (Fig. 1B). As a consequence, in wisp ${ }^{K G / D f}$ embryos which arrest after completion of meiosis upon fertilization [42, 47], the $b c d$ mRNA appeared in a broad anterior gradient (Fig. 1C), reminiscent of the final mRNA gradient at nc $14[7,11]$. Interestingly, the $b c d$ mRNA in wisp ${ }^{K G /}$ ${ }^{D f}$ mutants always remained at the cortex and was never transported into the interior of the egg nor of the oocyte, suggesting an intact non-permissive territory for $b c d$ mRNA transport [13].

When unfertilized wisp ${ }^{K G / D f}$ embryos were analyzed, we made interesting observations regarding the $b c d$ mRNA pattern: freshly laid embryos showed a broad anterior $b c d$ mRNA cap (Fig. 1D), as in fertilized and arrested wisp ${ }^{K G / D f}$ embryos, however, if unfertilized eggs were fixed $3 \mathrm{~h}$ after egg laying, the mRNA pattern was no longer retained to the cortex, but showed uniform movement into the egg (1E). A similar observation of an interiorwards movement of the $b c d$ mRNA in unfertilized (wild-type) eggs was observed in the past [11], however, there is a distinct difference: in wild-type eggs, the interiorwards movement of the $b c d$ mRNA followed a defined path, ascribed to the existence of a defined interior microtubular transport system, while in wisp ${ }^{K G /}$ ${ }^{D f}$ unfertilized embryos, movement of the $b c d$ mRNA appeared randomly throughout the interior of the egg. This observation suggests that proper polyadenylation is crucial for establishing the cytoarchitecture of the egg, consistent with the observation that wisp ${ }^{K G / D f}$ embryos stop development at nc 1 at the moment when meiosis is completed [42, 47].

To analyze the spatial pattern of both poly A polymerases, we employed specific antibodies against each protein $[41,47]$. We used a fixation method that allowed high sensitivity combined with low background caused by low autofluorescence from the egg [13, 21, 48]. Interestingly, both Wispy and PAP2 proteins showed cytoplasmic localization and were excluded from the nucleus at nc 14 (Fig. 1F-K), consistent with data on Wisp localization [26], however in conflict to the reported nuclear localization of PAP2 at that stage [41].

\section{Altering the Bcd gradient through modulation of Wispy}

Since it was known that the poly A tail length of the $b c d$ mRNA changes with time and alters the translation efficiency of the Bcd protein [33,34], it was conceivable to investigate if modulation of the activities of the two poly A polymerases would also alter the Bcd gradient. Overexpression of PAP2 was shown to increase the poly A tail of $b c d$ mRNA during oogenesis as well as in embryogenesis, but conferred early embryonic lethality during the first nuclear cycles [41]. Hence, analysis on the effect on the $b c d$ gradient during later nuclear cycles was impossible. wisp over-expression during the germ-line, however, did not confer early embryonic lethality, nor did it affect growth and morphogenesis of the oocyte, thus was suitable for testing the effect on $b c d$ gradient formation. To evaluate the extent how the Bcd gradient is altered at Drosophila blastoderm, we chose a gap gene, empty spiracle (ems) and a pair-rule gene evenskipped (eve), respectively, as read-out systems. These genes were shown to readily respond to changes of the Bcd gradient, by shifting their expression domains along the anterior-posterior (A-P) axis [49-51]. In wild-type embryos, Ems was expressed in an anterior circumferential stripe with its anterior margin located around 


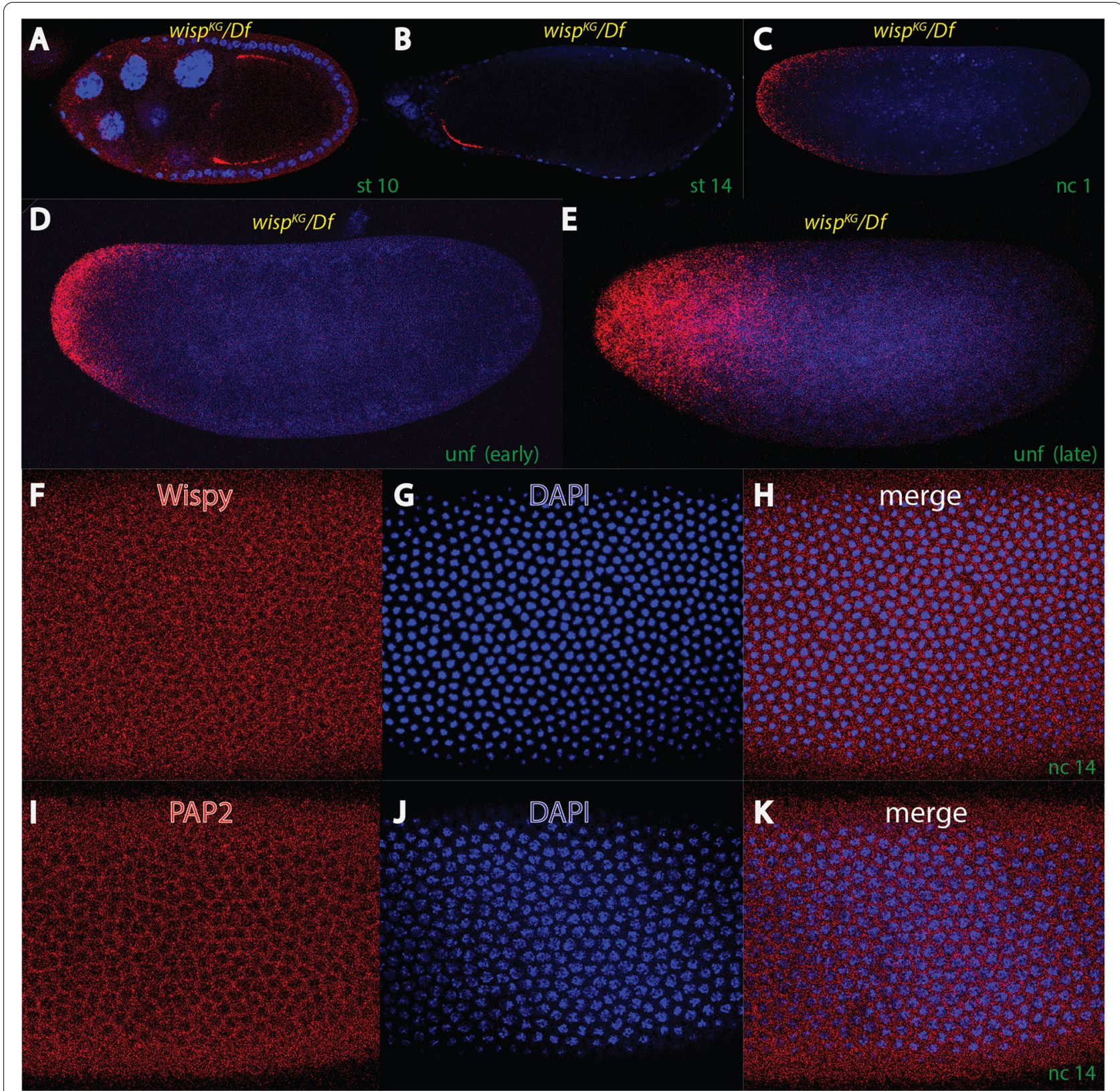

Fig. 1 bcd RNA distribution in wispy mutants and expression of Wispy and PAP2 in embryos. A-E in situ hybridization of wisp GK05287/Df(1)RA47 oocytes (A-B) and embryos (C-E) using bcd probes (in red) along with DAPI (in blue) to reveal nuclei. All panels are mid-sagittal single confocal sections mounted anterior end to the left and dorsal side up, where possible. In early staged oocytes, bcd mRNA is not transported to the anterior rim, rather it stays laterally in a stage $10(\mathbf{A})$ or stage 14 oocyte (B). Consequently, in a wisp ${ }^{G K 0287} / D f(1) R A 47$ embryo where growth is arrested during the first nuclear cycle (C), a deep cortical mRNA gradient is observed. In a freshly unfertilized wisp ${ }^{G K 0287} / D f(1) R A 47$ embryo (D), a similar steep cortical gradient is observed as in (C), while in an old unfertilized wisp ${ }^{G K 0287} / D f(1) R A 47$ embryo, the mRNA appears dispersed all over the anterior half. F-K single confocal sections on the apical surface of nuclear cycle 14 embryos, stained with anti-Wispy antibodies (F), DAPI staining (G) and the merge of both $(\mathbf{H})$, anti-PAP2 antibodies (I), DAPI staining $(\mathbf{J})$ and the merge of both $(\mathbf{K})$. Note that both poly A polymerases stain the cytoplasm and are excluded from the nuclei

$30 \%$ egg length (EL, $0 \%$ is anterior, $100 \%$ is posterior; Fig. 2B). Eve, on the other hand, was expressed in seven regularly-spaced stripes starting from around 30\% to 80\% EL (Fig. 2C).
If wisp was over-expressed (wisp ${ }^{O E}$ ), then statisticallysignificant shifts of the Eve stripes were observed: stripes 1 and 2 were shifted anteriorly (Fig. 2G, I, J), stripes 3 and 4 remained virtually unchanged (Fig. 2G, K, L), while 


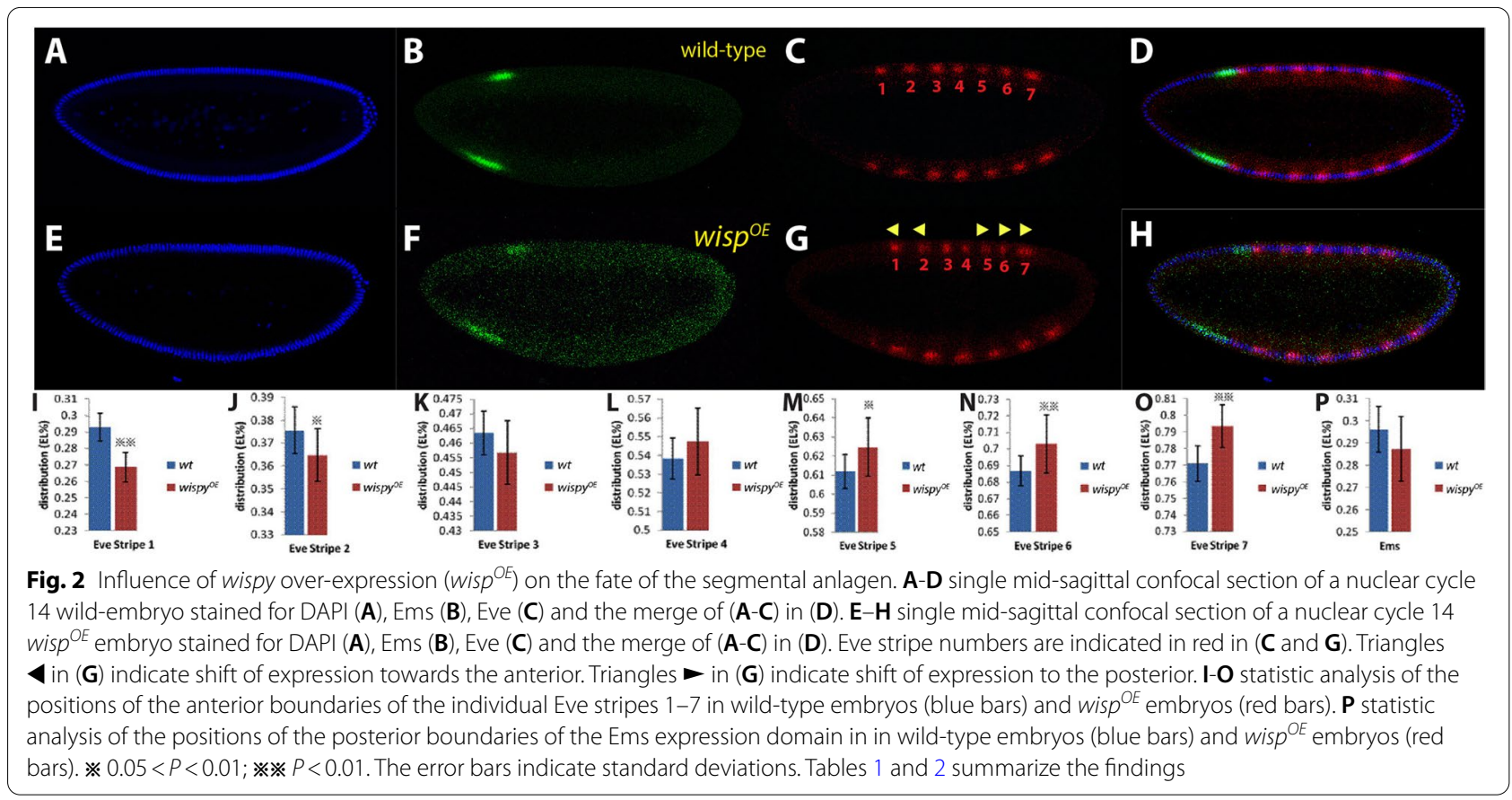

Table 1 Shift of Eve stripes in wild-type and wisp ${ }^{O E}$ mutants

\begin{tabular}{|c|c|c|c|c|c|c|c|c|c|}
\hline & $1^{a}$ & $2^{a}$ & $3^{a}$ & $4^{a}$ & $5^{a}$ & $6^{a}$ & $7^{a}$ & $\mathrm{~T}\left({ }^{\circ} \mathrm{C}\right)$ & $\mathrm{n}^{\mathrm{b}}$ \\
\hline wild type & $29.30 \% \pm 0.85 \%$ & $37.56 \% \pm 1.02 \%$ & $46.35 \% \pm 0.74 \%$ & $53.83 \% \pm 0.90 \%$ & $61.19 \% \pm 0.90 \%$ & $68.69 \% \pm 1.03 \%$ & $77.09 \% \pm 1.10 \%$ & 29 & 16 \\
\hline wispy $^{O E}(I)$ & $26.87 \%^{* *} \pm 0.88 \%$ & $36.47 \%{ }^{*} \pm 1.15 \%$ & $45.68 \% \pm 1.09 \%$ & $54.74 \% \pm 1.78 \%$ & $62.47 \%^{*} \pm 1.52 \%$ & $70.29 \%{ }^{* *} \pm 1.76 \%$ & $79.35 \%^{* *} \pm 1.28 \%$ & 29 & 13 \\
\hline
\end{tabular}

0-4 h embryos from wild-type and wispy ${ }^{O E}$ mutants were collected at $29^{\circ} \mathrm{C}$, respectively. Embryos were stained with an antibody against Eve. Eve stripes were measured by ImageJ. Data were analyzed by using student t-test ( $p$-value of 0.05 ) and reported as means \pm SE

${ }^{a}$ Eve stripes

${ }^{b}$ number of embryos examined

OE Overexpression

* $0.05<P<0.01 ;{ }^{* *} P<0.01$

Table 2 Shift of the Ems band in wild-type and wisp ${ }^{O E}$ mutants

\begin{tabular}{llll}
\hline & $\left.\mathbf{T}^{\circ} \mathbf{C}\right)$ & $\mathbf{n}^{\mathbf{b}}$ \\
\hline wild type & $29.61 \% \pm 1.06 \%$ & 29 & 16 \\
wispy $^{\circ E}(I)$ & $28.74 \% \pm 1.45 \%$ & 29 & 13 \\
\hline
\end{tabular}

0-4 h embryos from wild-type and wispy ${ }^{O E}$ mutants were collected at $29^{\circ} \mathrm{C}$, respectively. Embryos were stained with an antibody against Ems. Ems band was measured by ImageJ. Data were analyzed by using student t-test ( $p$-value of 0.05 ) and reported as means $\pm \mathrm{SE}$

${ }^{b}$ number of embryos examined

OE Overexpression

stripes 5-7 showed a posterior wards shift (Fig. 2G, M, $\mathrm{N}, \mathrm{O}$ ). The gap gene EMS, however, did not change significantly (Fig. 2G, P), but nevertheless followed the trend of Eve stripes 1 and 2. Since anteriorwards shifts of Eve stripes is a sign of decreased Bcd activity, posteriorwards shifts points towards an increased Bcd activity [3]. An combined interpretation of the shifts led to the conclusion that wisp ${ }^{O E}$ had a deteriorating effect on the Bcd gradient in the anterior part of the embryo, while it appeared attenuated in the posterior part. This would suggest that the exponential curve of Bcd in wild-type embryos following mathematical rules $[7,52]$ would be flatter in the anterior part, would exhibit "normal" levels in the middle, but would show higher levels in the posterior part in wis$p^{O E}$. It follows that wisp ${ }^{O E}$ will likely lead to a change in the segmental anlagen at blastoderm stage.

To corroborate the possibility of a shift of the anlagen at the blastoderm stage, we reasoned to analyze the cuticle pattern upon wisp ${ }^{O E}$. Several classes of cuticle phenotypes were observed, all centered around abdominal segments 3 to 5 (A3-5) with a "hotspot" at A4. The most frequent phenotype was a fusion of A3-5 (Fig. 3B), while a minor fraction of embryos showed deletion of A4 (Fig. 3C), interpreted as a milder form of the phenotype 


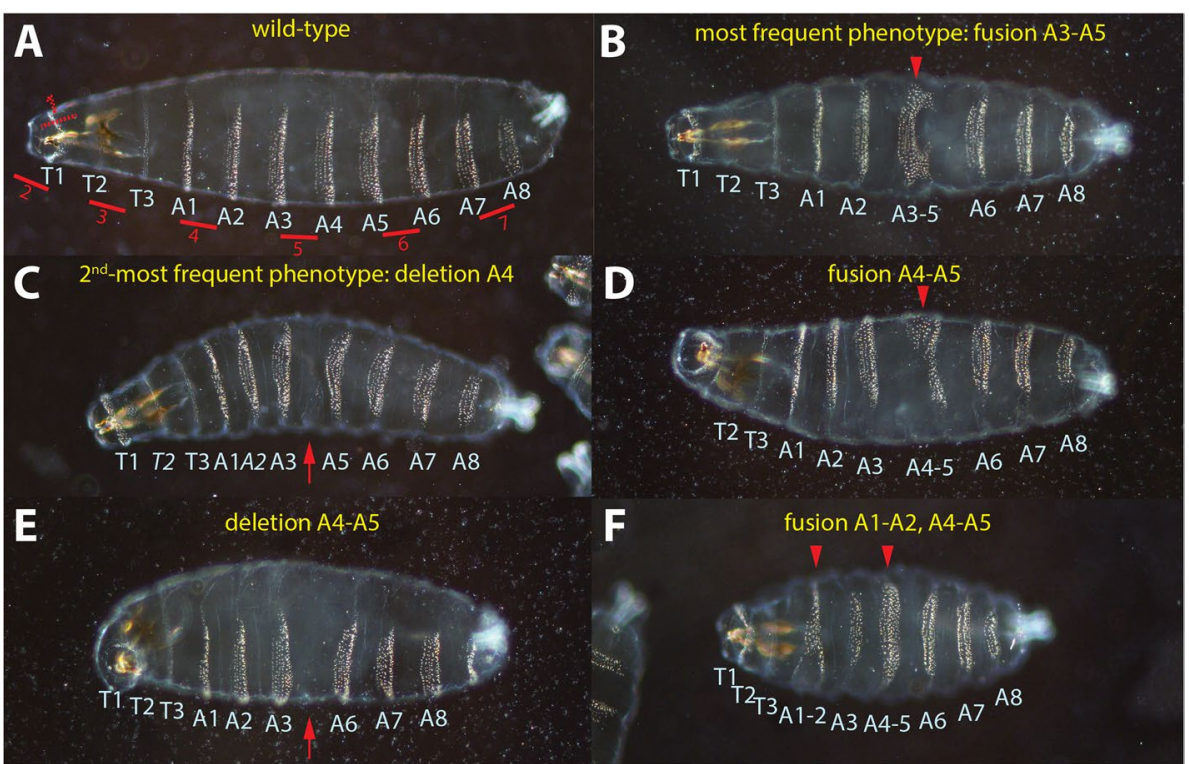

Fig. 3 Cuticle analysis of wispy over-expression (wisp ${ }^{O E}$ ). A cuticle of a wild-type larva serving as control. The larval body contains three thoracic (T1-T3) and eight abdominal (A1-A8) segments. The location of the Eve stripes at blastoderm stage are drawn and numbered in red with respect to their later position. Stripe 1 will affect internal structures and is drawn dashed. B embryo from a wisp ${ }^{O E}$ cross showing the most-frequent phenotype as fusion of A3-A5. C embryo from a wisp ${ }^{O E}$ cross showing the $2^{\text {nd }}$-most-frequent phenotype as a deletion of A4. D-F less-frequent phenotypes observed in embryos a wisp ${ }^{O E}$ cross showing fusion of $A 4$ and $A 5(\mathbf{D})$, deletion of both $A 4$ and $A 5(\mathbf{E})$ and pairwise fusions of $A 1$ and $A 2$ as well as $A 4$ and A5. Segmental fusions are indicated by red arrowheads, segmental deletions by red arrows

associated with fusion of A3-5. Further phenotypes that were observed were: fusion of A4-5 (Fig. 3D) and, as a more pronounced effect, a deletion of A4-5 (Fig. 3E) and pairwise fusions of A1-2 and A4-5 (Fig. 3F). [53] showed that the Eve stripes corresponded to uneven-numbered parasegments. We could note that the region centered around A3-5 corresponded to Eve stripes 5 and 6, both of which were significantly shifted to the posterior upon wisp ${ }^{O E}$.

\section{Spatial differences of the poly A tail length along the A-P axis.}

One of our working hypotheses for the altered Bicoid activity along the A-P axis was the question if the poly A tail length would change during the A-P transport of the $b c d$ mRNA as part of a larger RNP to the posterior. This hypothesis was fueled since it was shown that the $b c d$ mRNA particle consisted of several components, one of which turned out to be Wisp, because $b c d$ mRNA could be co-immunoprecipitated with Wisp [26]. Hence, it seemed conceivable to assume that the poly A tail of $b c d$ mRNA would be elongated while the mRNA migrated to the posterior. As a result, $b c d$ mRNAs located more posteriorly would exhibit a longer poly A tail than those that are located more anteriorly. A further consequence of this scenario would be that posterior $b c d$ mRNA molecules would possess a higher capacity to translate Bcd protein than anterior ones. Hence, this scenario would represent another level to control the establishment of the Bcd gradient, an aspect that was never considered in the past.

To tackle this hypothesis, we decided to mount ten staged nc 13 embryos into an embedding medium ensuring that embryo orientation and their anterior ends were aligned to one line. Subsequently, 3 serial sections of $60 \mu \mathrm{m}$ each were executed in the cryostat, followed by extraction of the RNA as described by [54]. The isolated RNA was then subjected to a PAT analysis, identical to that of [33] and the PCR products were fractionated on a $2.5 \%$ agarose gel (Fig. 4). Control lanes (lanes 4A-C) showed that the integrity of the RNA was maintained, although their concentration varied among the 3 samples. If assayed for $b c d$ poly A tail length, the first $60 \mu \mathrm{m}$ contained a smear with a prominent band at around 50 AAs (lane E). In the next $60 \mu \mathrm{m}$, the smear moved upwards, showing a prominent band at around 65 AAs (lane F), while the last $60 \mu \mathrm{m}$ analyzed showed a continuation of the upwards trend with a minor peak at around 75 AAs (lane G).

These data suggested that the length of the poly A tail indeed showed spatial variation and that more posteriorly-located $b c d$ mRNA particles possessed a longer poly A tail. This data points towards that Wisp may control the length of the poly A tail while being associated with the $b c d$ RNP [26]. Moreover, the few posteriorly-located 


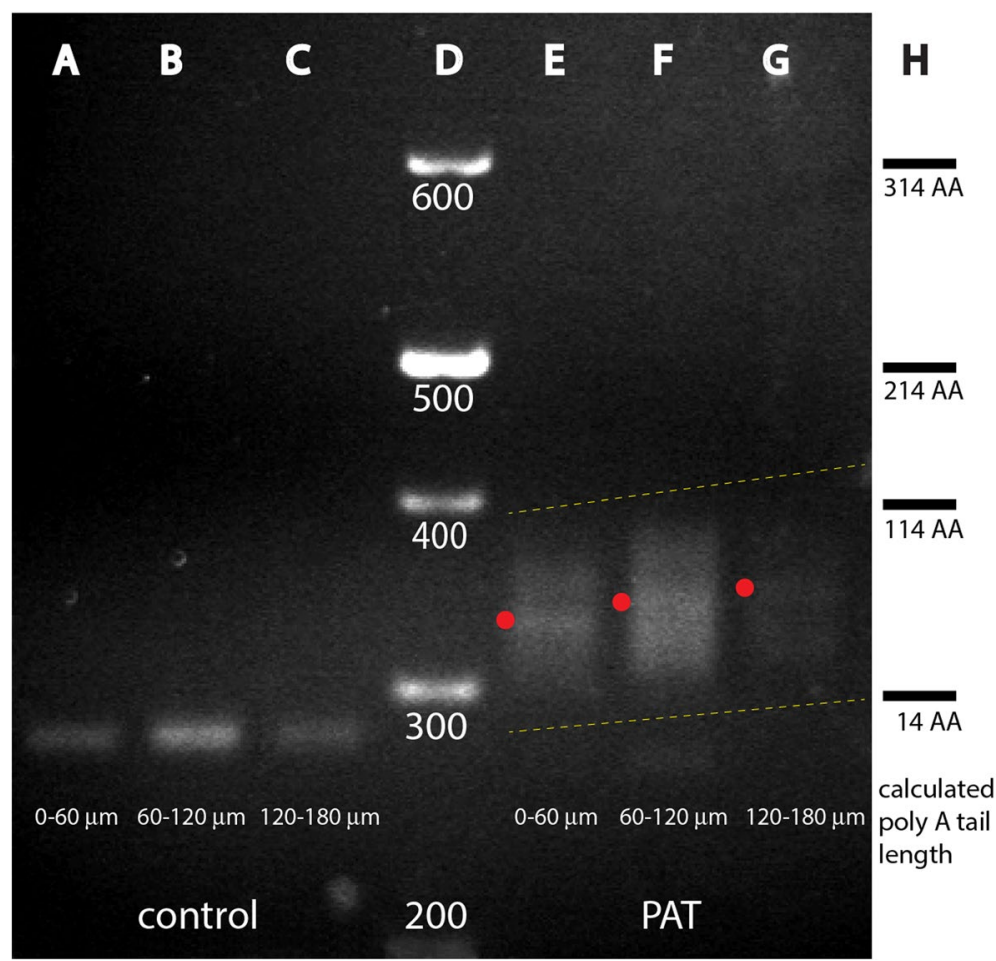

Fig. 4 Spatial distribution of poly A tail length of $b c d$ mRNA along the A-P axis of Drosophila using PAT analysis. Poly A tail (PAT) analysis of bcd mRNA isolated from 3 consecutive $60 \mu \mathrm{m}$ sections $(\mathbf{A}, \mathbf{B}, \mathbf{C} ; \mathbf{E}, \mathbf{F}, \mathbf{G})$ from ten $\mathrm{nc} 13$ embryos starting from the anterior tip and cutting to the posterior as indicated at the bottom. A, B, C internal PCR primer control of bcd to evaluate abundance and quality of the isolated RNAs. D DNA size marker. E, F, G PAT analysis showing increased sizes of smears suggesting that the poly A tail lengths change with the location along the A-P axis. $\mathbf{H}$ calculated poly A tail length

particles can translate Bcd stronger and thus may stretch the formation of the gradient to the posterior. We do not know, however, how long Wisp is associated the $b c d$ RNP and whether the association is constant over the A-P range.

\section{Modulating the action of bcd in time}

The Bcd gradient is established from the time of formation of the syncytial blastoderm and regulates the activity of gap genes and pair-rule genes during nc 11-14 [55]. While nature would ensure that the correct amount of Bcd protein would end up in every nucleus at nc 14, we pondered what would happen if the timely production of Bcd could be altered such that more than 14 nuclear cycles would be made available to the embryo, and what the consequences for the segmental anlagen at blastoderm would be. We expected that such a scenario would likely involve further transport of the $b c d$ mRNA to the posterior and longer exposure of the mRNA to polyadenylation. To test this hypothesis, we searched for mutations that would enable extra nuclear cycles during the syncytial blastoderm stage. One of them, maternal haploid ( $m h$ ) [56-60], a maternal effect mutation encoding a metalloprotease enriched at the largest satellite repeats seemed suitable to test this hypothesis. We used $m h^{1}$, an allele that occasionally allows progression through a $15^{\text {th }} \mathrm{nc}$, but soon afterward confers embryonic lethality $[56,57]$.

We first checked how the $b c d$ mRNA gradient would be affected in embryos from $m h^{1} / m h^{1}$ mothers. Around $10 \%$ of $m h^{1} / m h^{1}$ embryo reached the cellular blastoderm stage and exhibited a higher number of blastoderm nuclei due to an extra round of nuclear division, hence are at nc 15. Since the number of nuclei at cellular blastoderm, usually $\sim 6000$ nuclei in wild-type embryos, was limited due to space constraints, many of these extra nuclei appeared now displaced towards the yolk (Fig. 5B, arrowheads). As far as the mRNA gradient was concerned, in nc $15 m h^{1} / m h^{1}$ embryos, the $b c d$ mRNA gradient appeared indistinguishable from that of wildtype nc 14 embryos (Fig. 5A, C). Basal to apical transport of the mRNA, normally occurring during the first 15 min of nc 14 in wild-type embryos [7], occurred in nc 15 , instead (data not shown). This data suggests that the formation of the $b c d$ mRNA gradient appears independent of the number of nuclear cycles. 


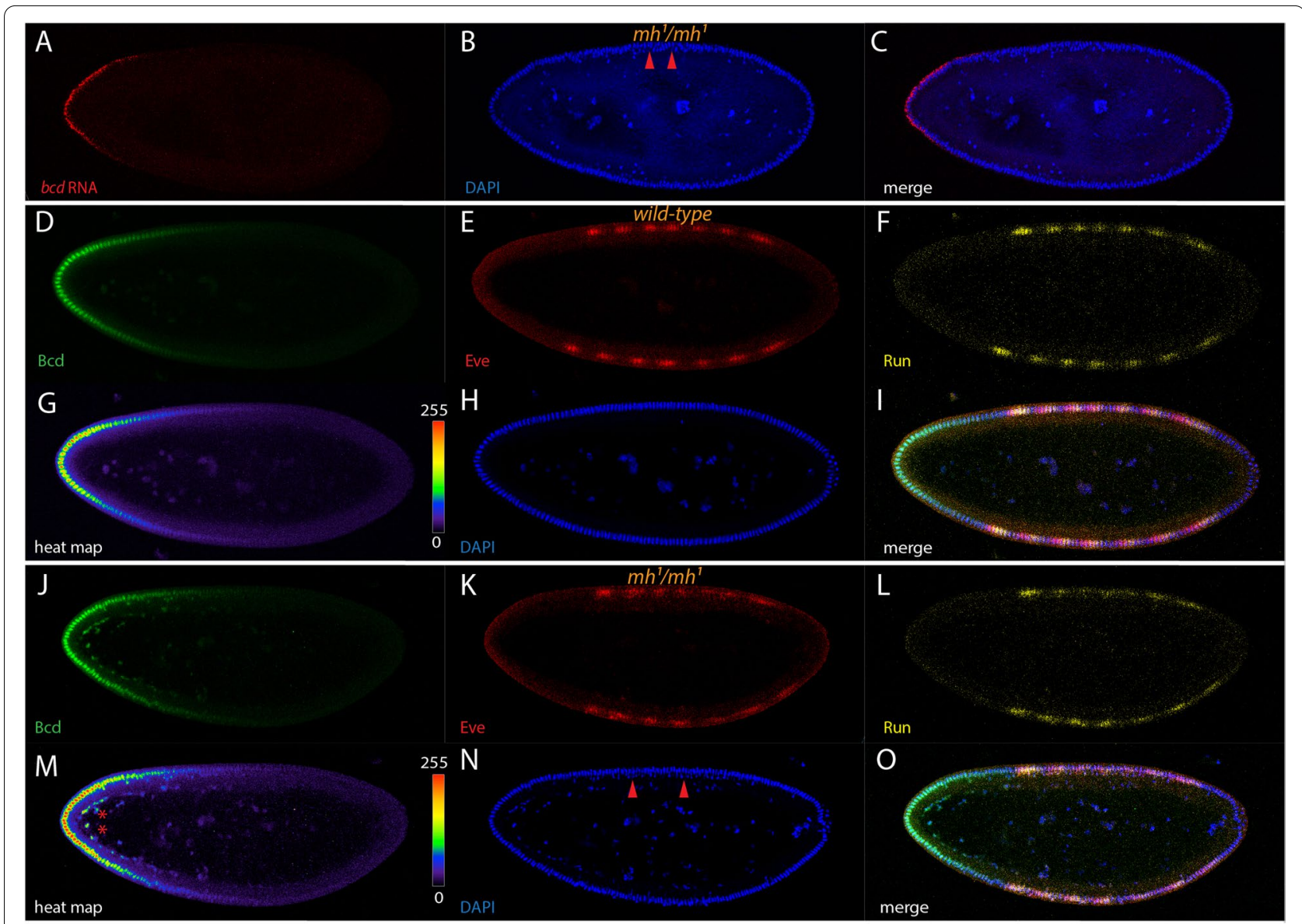

Fig. 5 Modulation of the bcd gradient by an extra nuclear cycle. Pictures represent midsagittal confocal planes of embryos oriented with their dorsal side up and anterior to the left. A-C a nc 15 embryo from $m h^{1} / m h^{1}$ mothers stained for $b c d m R N A(A$, red), DAPI (B, blue) and the merge of (A-B) in (C). Note the double layer of nuclei due to an extra round of nuclear division, arrowheads in (B and $\mathbf{N}$ ). D-I a nc 14 wild-type embryo stained for Bcd protein (D, green), Eve (F, red), Run (G, yellow), heat-map of the intensities of Bcd protein concentrations including scale from 0-255 $(\mathbf{G})$, DAPI (H, blue) and the merge of (D-F, H) in (I). J-O nc 15 embryo from $m h^{1} / \mathrm{mh}^{1}$ mothers stained for Bcd protein $(\mathbf{J}$, green), Eve (K, red), Run (L, yellow), heat-map of the intensities of Bcd protein concentrations including scale from 0-255 (M), DAPI ( $\mathbf{N}$, blue) and the merge of $(\mathbf{J}-\mathbf{L}, \mathbf{N})$ in $(\mathbf{O})$

We then focused on the appearance of the Bcd protein and used a set of pair-rule genes, Even-skipped and Runt, to monitor the appearance of downstream targets in relation to the Bcd gradient by using triple antibody staining. Moreover, we highlighted the appearance of the Bcd gradient using a heat-map analysis to eventually detect subtle changes in the gradient $[7,13]$.

In wild-type nc 14 embryos, Bcd formed an impressive gradient (Fig. 5D, G) and the two pair-rule genes, Eve (Fig. 5E) and Runt (Fig. 5F) appeared as 7 stripes, respectively, with distinct relative phasing to each other (Fig. 5I). In nc $15 m h^{1} / m h^{1}$ embryos, it could be noted that the Bcd gradient appeared indistinguishable from that in wild-type embryos (Fig. 5J, M), as did the mRNA analysis (Fig. 5A, C). However, we could note that the surplus of internalized nuclei at the anterior side were strongly filled with Bcd (Fig. 5J, M) suggesting that more Bcd was produced than in a comparable nc14 wild-type embryo (Fig. 5D, G). Of note, the gradient appeared normal (Fig. 5M), compared to wild-type (Fig. 5G). Regarding the fate map of the segmental anlagen, no changes were apparent, as the relative positions of both Eve (Fig. 5K) and Run (Fig. 5L) stripes along the A-P axis appeared unchanged, compared to the respective wild-type situation (Fig. 5E, F). From this data, we could conclude that altering the timely action of $b c d$ did not lead to a change in the intrinsic properties of the gradient.

\section{Genetic manipulation of Bcd movement}

Recent studies showed that the movement of Bcd strongly depended on an intact cytoarchitecture of the 
early Drosophila egg $[1,13]$. In those studies, it became evident that Bcd never moved into the inner core of the egg, but rather stayed at and moved along the cortex. Hence, the inner core defined a non-permissive territory [13], in agreement with the proposed mechanisms associated with the ARTS model [7]. However, [13] could demonstrate that the properties of inner core could be altered, upon administration of small molecules against microtubules that compromise its cytoarchitecture, such that the core became permissive. As a consequence, in drug-administered eggs, Bcd moved along a broad front into the egg and thus appeared to conform the SDD model [13].

We then wondered if we could identify genes that upon inactivation would allow movement of Bcd into the inner core of the embryo instead. Among the many genes tested, one gene, $C y c l i n B,(C y c B)$ [61-63], when knocked-down, showed the desired effect (Fig. 6). Cyclin $B$ is involved in regulation of nuclear cycles, in particular the entry point into mitosis in conjunction with Cdk1 [64], as well as in controlling the length of microtubules [63].

We first analyzed the behavior of $b c d$ mRNA in $C y c B$ mutants using $R N A^{i}$ lines in combination with a maternal driver, termed $C y c B^{i}$. $C y c B^{i}$ mother did not produce many eggs due to fact that oogenesis was compromised. Moreover, $C y c B^{i}$ embryos were smaller in size and showed early embryonic lethality with halted development during the first four nuclear cycles, consistent with observations from [62]. The $b c d$ mRNA pattern did not show any marked change compared to wild-type and the mRNA stayed at the anterior pole, although the anterior cap did not show the compacted form as in wild-type embryos Fig. 6A;
[7, 65]. Due to the fact that $C y c B$ also controls the length of microtubules [62], we analyzed the behavior of MTs using $\mathrm{YL}_{1,2}$, a monoclonal antibody previously shown to detect the MT network that is responsible for transporting the $b c d$ mRNA to the posterior [7, 11]. In $C y c B^{i}$ embryos, many cortical (Fig. 6C), but also internal (Fig. 6D) MT asters were detected, similar to the ones detected in $\alpha T u b 67 C^{3}$ embryos [11]. Of note, none of these asters were associated with a MTOC in vicinity of nuclei, hence represented autonomous aggregations of MTs into asters. Moreover, the number of cortical MT threads was markedly increased. By combining a whole Z-stack to obtain a 3-D picture, many random MT asters and a dense MT network could be detected that were not associated with nuclei (Fig. 6H). Thus, in $C y c B^{i}$ mutants, the MT pattern appears random and $C y c B^{+}$appears to suppress these asters. Possibly, due to absence of any mitotic cycles and its major regulator $(C y c B)$, a surplus of free MT monomers is available to enable a self-organizing process creating these asters.

Next, we analyzed the Bcd protein pattern in $C y c B^{i}$ embryos. In contrast to the mRNA (Fig. 6A), the protein showed a complete different pattern (Fig. 6E, G). Instead of moving along the cortex in a coordinated manner with time [13], a portion of the protein moved to the interior in a broad front, best seen in the heat-map analysis (Fig. 6G). This type of movement is highly reminiscent in embryos that were treated with the MT-degrading drug Vinblastine [13], thus appeared to conform the SDD model. Moreover, internal nuclei were filled with Bcd protein suggesting that the changed cytoarchitecture of the non-permissive territory of the inner core enabled movement of Bcd deeply into the interior.

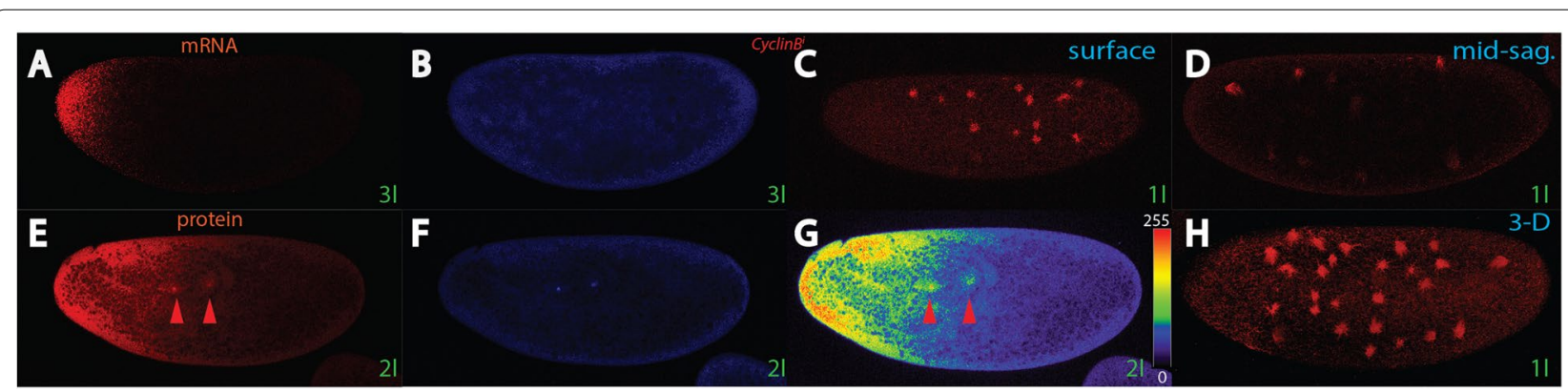

Fig. 6 Modulation of the Bcd gradient by Cyclin B. Pictures represent midsagittal confocal planes of embryos oriented with their dorsal side up and anterior to the left, except $(\mathbf{C}, \mathbf{H})$. A, B a nc 3 CycB RNA i embryo stained for bcd mRNA (A) and DAPI (B). C, D, H a nc 1 CycB RNA ${ }^{i}$ embryo stained with mab $\mathrm{YL}_{1,2}$ detecting freshly-made tubulin, and analyzed as a surface confocal Z-stack section (C) and a mid-sagittal confocal Z-stack of the same embryo (D), as well as a 3-D reconstruction combining multiple Z-stacks of the same embryo in (C, D) to reveal the microtubular pattern in the outermost $30 \mu \mathrm{m}$ of the cortex. E, F mid-sagittal nc 2 CycB RNA i embryo stained with Bcd antibody. Arrowhead denote filling of nuclei with Bcd. $\mathbf{G}$ heat-map of the intensities of Bcd protein concentrations in embryo (E) including scale from 0-255. Arrowhead denote filling of nuclei with Bcd. $\mathbf{H}$ surface 3-D reconstruction of the confocal stack used in (C, D) to demonstrate extensive formation of spontaneous asters, despite lack of MTOCs at the cortex. Stages of embryos are denoted in green and follow the nomenclature of [12] 


\section{Discussion}

We have shown that several parameters have a profound effect on the formation and appearance of the bicoid gradient, as well as movement of the Bicoid protein in the Drosophila embryo. The first parameter concerned the translation efficiency of $b c d$ mRNA and consequences for the Bcd gradient and its intrinsic information. The second one pertained to the duration where $b c d$ was active and how this affected the position of the segmental anlagen. The third one applied to a genetic influence on the cytoarchitecture that ultimately led to a completely different Bcd movement.

Physical interaction studies using microarray analysis involving the Wisp poly A polymerase as bait revealed that Wisp interacted with a plethora of mRNAs, among those $b c d$ mRNA was also detected [26]. Since $b c d$ mRNA is incorporated in a larger RNP which contains many other proteins such as Staufen [25], it appeared conceivable to assume that Wisp, for a certain time interval was physically associated with the RNP complex. Since Wisp localization was cytoplasmic (Fig. 1F, [43], a possible scenario could be that Wisp would have access to the RNP for poly A tail modification of the $b c d$ mRNA, but only when the RNP transport along MTs was halted. This scenario would be consistent with the proposed mechanism where the mRNA is transported when the MTs are built up. However, since the MT network for transport was only built up during Metaphase and early Anaphase, while being non-existent during the remaining phases of a nuclear cycles, it could transport the mRNA during a short time interval of a nuclear cycle. Thus, Wisp would have the majority of a nuclear cycle at its disposition to act on $b c d$ mRNA because the RNP is not moving. Another scenario would be that Wisp is integral part of the RNP and moves with it to the posterior.

In the past, efforts were made to investigate on intrinsic functions of either the $b c d$ mRNA or the Bcd protein that would play a role in gradient formation. On the mRNA side, a motif immediately downstream of the stop codon was shown to mediate stability of the mRNA [32], or a nonamer sequence further downstream that was shown to be important for its localization [66], along with studies that revealed the binding sites on the $b c d$ mRNA for the RNA-binding protein Staufen [25]. Furthermore, it was shown that $b c d$ mRNA always assembled as a dimer within the RNP and the assembly could be attributed to a cis-element responsible for dimerization that is localized in a stem-loop domain (domain III), [31]. Now, in this report, we added another tool to shape the gradient via an intrinsic function: the poly A tail length function controlling the translation efficiency, combined with spatial differences of the poly A tail length along the A-P axis (Fig. 4). We wish to propose this mechanism to raise the initial positional information defined by the mRNA gradient to the next level, with help of differential translation efficiency of the mRNA along the A-P axis. From previous studies, it became evident that the mRNA gradient extended far to the posterior, at least to $40 \% \operatorname{EL}[7,8,11]$, and may extend even further to the posterior, currently hampered by restrictions in the sensitivity of the RNA in situ detection technique. Hence, the few $b c d$ RNPs that could be transported to the far posterior most likely contribute with a higher efficiency to locally translate Bcd protein and thus are able to modify the pre-pattern mRNA gradient.

Recently, it was demonstrated that the translation efficiency of ribosomes of the early Drosophila egg is not linear along the A-P axis, exemplified by an analysis on the gap gene hunchback $(h b)$ [67]. A completely new hallmark of this report was that $h b$ expression levels would not only be dependent on the binding of the necessary transcription factors driving the gene, e.g. by $b c d$, but also at the level of translation. It was then proposed that translation of hunchback would be controlled by other trans-acting factors and that this regulated hunchback translation would constitute another tool to shape the expression of $h b$ along the A-P axis. Likewise, we wish to propose that the translation of $b c d$ could be controlled not only by its intrinsic properties, such as the length of its poly A tail, but also by trans-acting factors such as miRNAs, known to regulate translation of protein across most phyla [68]. Consistent with this observation, the 3'UTR of $b c d$ contains a highly-conserved motif for binding to miR305 (FlyBase; [69]) immediately upstream of the stability motif [32]. Moreover, miRNA 305 was shown to be one of the major inhibitor for Bcd translation in the oocyte [70] through binding of miRNA 305 to this highlyconserved motif.

Our studies demonstrated that manipulating the time when Bicoid is active and for how long it can act did not have a profound effect on the regulation of the cascade of segmentation genes (Fig. 5). While the result was rather surprising, it suggests that possibly the segmental anlagen are defined already at nc 14 , likely through Bcd, and that this definition is locked afterwards. An alternative interpretation could be that the definition of the segmental anlagen is also depended on other determining factors, and thus not solely dependent on Bcd.

\section{Increased sensitivity of abdominal segments A4 and A5 upon perturbations}

Manipulation of the Bcd gradient in Fig. 2 revealed that the changes were not linear, e.g. a linear posteriorward shift of the Eve stripes as observed in Drosophila 
mutants that provide a higher Bcd dose [13, 71]. Rather, the anterior two stripes moved to the anterior and the posterior three stripes moved to the posterior. Stripes 3 and 4 remained unchanged and thus represented a fixed point where the exponential Bcd intensity curve $[7,52]$ was turned slightly counter-clockwise at the position of Eve stripes 3 and 4 to define a new decay curve. Anterior to this position, the curve was lowered, posterior to this position, the curve appeared elevated. Consistent with this proposal, the cuticle region corresponding to Eve stripes 3 and 4, T2/T3 and A1/A2, respectively appeared mostly unaffected (Fig. 3). This raises the critical question why the region of A3 to A5, corresponding to parasegments $9-11$ is particularly sensitive to changes in the cuticle. One explanation could be that the over-expressing driver line dumps GAL4 protein non-uniformly into the egg, or the protein translation properties of this region are not identical to that of the rest of the embryo.

\section{The problem with the rescue of the bcd phenotype.}

In the past, many reports validated their transgenic $b c d$ constructs by analyzing the phenotypic consequences or the behavior of e. g. a Bcd-GFP fusion in a $b c d^{-}$background by scoring the larval cuticle for full rescue $[4,6$, $72-81]$. We wish to remind the community that this is an easy way out to "validate" a $b c d$ construct, but does not fully reflect the biological function of Bcd for the patterning process. This notion is based on the following two arguments: 1) even under conditions where the segmental anlagen are shifted in one direction, e. g. to the posterior, through increased doses of Bcd, the resulting larval pattern is normal. This apparent conundrum resolves because correction mechanisms during later stages are in play that restore the faulty programming of the segmental anlagen back to wild-type $[13,77,82]$. 2) The $b c d^{E 1}$ allele [2] that was used in all cases to provide a $b c d$-null background is not a true $b c d$ null allele, as it only removes the activity of the large $b c d$ isoforms. Complete removal of the $b c d$ locus has a much stronger embryonic phenotype than any strong $b c d$ allele, e.g. $b c d^{E 1}$ (Baumgartner, manuscript), which makes claims on any role of $b c d$ subject to another through revision.

\section{Bcd movement in $C y c B$ mutants appears to fit the SDD model}

In the past, the SDD model has been the predominant model to explain the occurrence of the Bcd gradient [3, $5,6]$. The model also proposed that Bcd would diffuse uniformly throughout the egg, fueled by simulation studies using fluorescent Dextran particles [83] which indeed showed a broad inwards movement of the particles and thus appears to fit the SDD model. Unfortunately, in these studies, it was never taken into consideration that the composition of the egg may not be uniform, but rather would contain territories shown to have a profound effect on Bcd movement $[1,13]$. The two territories, the cortex and the inner core were already discovered several decades ago [12, 84], but were never discussed in conjunction of Bcd movement.

$C y c B$ is the first identified genetic component that had a profound effect on Bcd movement. When compromised, Bcd was allowed to migrate into the interior non-permissive territory (Fig. 6) and thus appeared to conform the SDD model. $C y c B$ is a regulator of microtubule activity and length, however, the gene is dispensable for mitosis and embryonic viability [85]. Absence of $C y c B$ affected oocyte growth, leading to reduced yield in eggs [62]. At the molecular level, lowering the doses of $C y c B$ increased the occurrence of microtubular asters, often resulting in thick and long microtubules and increased numbers of asters without nuclei in the center [62], in agreement with our $C y c B^{i}$ analysis (Fig. 6H). Possibly, the pool of available Tubulin monomers is affected which ultimately may weaken the Tubulin cytoarchitecture in the interior of the egg and thus allows Bcd to penetrate the inner yolk. Similar formation of spontaneous asters were detected in a weak $\alpha$ Tub67C mutation [11], however, no data were made available regarding Bcd movement. We can conclude that $C y c B$ is a regulator of the cytoarchitecture of the non-permissive territory located in the interior, most likely by weakening the microtubular integrity of this territory.

\section{Conclusion}

We have shown, through a number of experiments that the formation and appearance of the Bcd gradient is probably far more complex than previously thought and that this process involves a plethora of factors that help to shape the gradient. We demonstrated that the Bcd gradient formation is based on trans-acting factors that were previously not considered to exist. Hence, this data may open our view and may lay the foundation for further discoveries how Bcd gradient formation is governed.

\section{Materials and methods}

\section{Drosophila stocks and genetics}

Canton-S stock from Bloomington (No. 64349) was used as control. The wispy overexpression (wisp ${ }^{O E}$ ) stocks were generated by cloning a wispy full-length cDNA (based on RE03648, kindly provided by M. Simonelig) into a modified pUASP vector (kindly provided by $M$. Simonelig) where the K10 3'UTR was replaced by the SV40 3'UTR. This step is absolutely essential, as the K10 3'UTR appears to be regulated by wispy (M. Simonelig, pers. comm.). Standard germline transformations 
were performed by BestGene (USA). The wispy mutant in Fig. 1 was wisp ${ }^{K G 05287}$ (Bloomington stock \# 16,467) and was used in combination with the deficiency $D f(1)$ RA47 (Bloomington stock \# 961), as described in [43]. The $y^{1} w^{a} m h^{1} / F M 7 a$ stock was from Bloomington, stock number 7130. The $C y c B \mathrm{RNA}^{\mathrm{i}}$ stock was $P[$ TriP.CycB${ }_{H M S 01871}$ attP2, Bloomington stock number 38957 . The $2^{\text {nd }}$-chromosome maternal GAL4-driver line V32 was obtained from the Perrimon lab and was used for all over-expression and $R N A^{i}$ experiments at $29^{\circ}$. Flies were fed with standard fly food (Bloomington recipe) and were exposed at $29^{\circ} \mathrm{C}$ to boost the efficacy of the maternal GAL4 driver.

\section{Cuticle preparations}

Embryos were collected in $24 \mathrm{~h}$. interval, incubated $>36$ h., dechorionated in $50 \%$ bleaching solution, fixed in $25 \%$ formaldehyde for $>5 \mathrm{~h}$., devitellinized, mounted in Hoyer's medium and incubated at $65^{\circ} \mathrm{C}$ for $3-5$ days, as described [13].

\section{Antibody staining and fluorescent in situ hybridization}

Embryos were heat-fixed for immunostaining. Rabbit antibodies against wispy and PAP2 were obtained from M. Wolfner and M. Simonelig, respectively, and were both used at 1:1000. The monoclonal antibody against Eve (DSHB) was used at 1:250. Rabbit-anti-Bcd antibodies [11] were used at 1:1000, Guinea pig antibodies against Run were obtained from Kuni Saito and were used at 1:1000, rabbit-anti-Ems antibodies were obtained from Uwe Walldorf and were used at 1:1000, DAPI for nuclear staining was used at $1 \mu \mathrm{g} / \mathrm{ml}$. Rat monoclonal antibody $\mathrm{YL}_{1,2}$ to detect freshly-made Tubulin [11] was used at 1:1000. For color conversion and interpretation of signal intensities, the OsiriX DICOM program was used [86].

The protocol for fluorescent in situ hybridization was adopted from [11], except that RNA probes were tagged with an Alexa Fluor 568 Signal-Amplification Kit (Invitrogen A11066).

\section{Embryo slicing, RNA extraction and PAT analysis}

Embryos were mounted in OCT perpendicular to the blade of a Cryostat. Consecutive sections of $60 \mu \mathrm{m}$ starting from the tip of $10 \mathrm{nc} 13$ wild-type embryos similar to the method as described by [54] were performed. RNA from the sections was isolated in $\mathrm{TRIzol}^{\mathrm{TM}}$ and qualitychecked for degradation in a Bioanalyzer RNA pico chip. RNA was further concentrated using the direct-zol ${ }^{\text {TM }}$ RNA MiniPrep Plus kit (Catalogue number \#R2070) and a Zymo-spin ${ }^{\mathrm{TM}}$ IIICG column. DNase treatment was done directly on the column, followed by washing and elution with water. The length of the poly A tail was examined using the USB ${ }^{\circledR}$ poly A tail-Length Assay Kit (ThermoFisher, Catalogue number \#76,455), following the manufacturer's recommendation. The starting material had a RNA concentration in the range of $0.2 \mathrm{ng} / \mu \mathrm{l}$. Two primer sets were used for amplification, one $b c d$ genespecific primer set giving a defined length and serving as control for integrity and concentration of the RNA (left side) and one primer set to amplify the gene of interest including the poly A tail (right side). The $b c d$ genespecific forward primer was 5'-CATTTTGCGCATTCT TTGACC-3' and the $b c d$ gene-specific reverse primer was 5'-TGTGTAGTTAGTCACAATTTACCC-3.' For poly A tail length determination, the $b c d$ gene-specific forward primer again was 5'-CATTTTGCGCATTCT TTGACC-3', identical to that described in [33], while the reverse primer was provided by the kit. PCR products were analyzed on a $2.5 \%$ agarose gel. The size of the amplified cDNA is $286 \mathrm{bp}, 256 \mathrm{bp}$ from $b c d$ and $30 \mathrm{bp}$ from the anchor.

\section{Data analysis}

All images were recorded using a Zeiss LSM 710 confocal microscope. Images were post-processed with Adobe Photoshop and Adobe Illustrator. Image J was used to measure the length of the embryos, the distance between the anterior tip, the anterior border of each Eve stripe and the posterior border of Ems. All data was analyzed with Analysis of Variance (ANOVA) and two-tailed Student's t-tests. Data are reported as means $\pm \mathrm{SE}$.

\section{Abbreviations \\ bcd: bicoid; hb: hunchback; ems: empty spiracles; eve: even-skipped; run: runt; PAP2: poly A polymerase 2; wisp: wispy; CycB: Cyclin B; MT: Microtubule; ARTS: Active mRNA transport, synthesis; SDD: Synthesis, diffusion, degradation; MTOC: Microtubule organizing center; LD: Lipid droplet; EL: Egg length; AA: Amino acid.}

\section{Acknowledgements}

S. B. thanks the Swedish Research Council, the Ekhaga -, Pia Ståhl -, Nilsson Ehle - and the Erik Philip-Sörensen-Foundation for support. S. B. wishes to thank Thomas Mayer for hosting him during a sabbatical stay in 2018 and subsequent years. We wish to thank Martine Simonelig for providing anti-PAP2 antibodies and Mariana Wolfner for providing anti-Wispy antibodies, Kuni Saito for the Run antibody, Uwe Walldorf for the Ems antibody, and Linda Wei for comments on the manuscript.

\section{Authors' contributions}

X. C. and I. R. were responsible for producing and analyzing the data of Figs. 1-6. X. C. and S. B. wrote the manuscript. The authors read and approved the final manuscript.

\section{Funding}

Swedish Research Council, award number 2010-4358.

Ekhaga Foundation.

Pia Ståhl Foundation.

Nilsson Ehle Foundation.

Erik Philip-Sörensen Foundation.

Open access funding provided by Lund University. 


\section{Availability of data and materials}

The datasets generated during and/or analyzed during the current study are available from the corresponding author on reasonable request.

\section{Declarations}

\section{Ethics approval and consent to participate}

Not applicable.

\section{Consent for publication}

Not applicable.

\section{Competing interests}

The authors declare that they do not have any competing interests.

\section{Author details}

${ }^{1}$ Departmentof Experimental Medical Sciences, Lund University, BMC D10, 22184 Lund, Sweden. ${ }^{2}$ Present address: Hubrecht Institute, 3584 CT Utrecht, The Netherlands. ${ }^{3}$ Department of Biology, University of Konstanz, 78457 Konstanz, Germany.

Received: 28 May 2021 Accepted: 19 July 2021

Published online: 17 August 2021

\section{References}

1. Baumgartner S. Seeing is believing: the Bicoid protein reveals its path. Hereditas. 2018;155:28.

2. Frohnhöfer HG, Nüsslein-Volhard C. Organization of anterior pattern in the Drosophila embryo by the maternal gene bicoid. Nature. 1986;324:120-5.

3. Driever W, Nüsslein-Volhard C. A gradient of bicoid protein in Drosophila embryos. Cell. 1988;54(1):83-93.

4. Little SC, Tkacik G, Kneeland TB, Wieschaus EF, Gregor T. The formation of the Bicoid morphogen gradient requires protein movement from anteriorly localized mRNA. PLoS Biol. 2011;9(3):e1000596.

5. Grimm O, Coppey M, Wieschaus E. Modelling the Bicoid gradient. Development. 2010;137(14):2253-64.

6. Gregor T, Wieschaus EF, McGregor AP, Bialek W, Tank DW. Stability and nuclear dynamics of the bicoid morphogen gradient. Cell. 2007;130(1):141-52.

7. Spirov A, Fahmy K, Schneider M, Frei E, Noll M, Baumgartner S. Formation of the bicoid morphogen gradient: an mRNA gradient dictates the protein gradient. Development. 2009;136(4):605-14.

8. Frigerio G, Burri M, Bopp D, Baumgartner S, Noll M. Structure of the segmentation gene paired and the Drosophila PRD gene set as part of a gene network. Cell. 1986;47(5):735-46.

9. Weil TT, Forrest KM, Gavis ER. Localization of bicoid mRNA in late oocytes is maintained by continual active transport. Dev Cell. 2006;11(2):251-62.

10. Weil TT, Parton R, Davis I, Gavis ER. Changes in bicoid mRNA anchoring highlight conserved mechanisms during the oocyte-to-embryo transition. Curr Biol. 2008;18(14):1055-61.

11. Fahmy K, Akber M, Cai X, Koul A, Hayder A, Baumgartner S. alphaTubulin 67C and Ncd are essential for establishing a cortical microtubular network and formation of the Bicoid mRNA gradient in Drosophila. PloS one. 2014;9(11):e112053.

12. Foe VE, Alberts BM. Studies of nuclear and cytoplasmic behaviour during the five mitotic cycles that precede gastrulation in Drosophila embryogenesis. J Cell Sci. 1983;61:31-70.

13. Cai X, Akber M, Spirov A, Baumgartner S. Cortical movement of Bicoid in early Drosophila embryos is actin- and microtubuledependent and disagrees with the SDD diffusion model. PloS one. 2017;12(10):e0185443.

14. Thukral S, Kaity B, Dey B, Sharma S, Nandi A, Mitra MK, Rikhy R. Cyto-architecture constrains the spread of photoactivated tubulin in the syncytial Drosophila embryo. Int J Dev Biol. 2020;64(4-5-6):275-87.

15. Baker J, Theurkauf WE, Schubiger G. Dynamic changes in microtubule configuration correlate with nuclear migration in the preblastoderm Drosophila embryo. J Cell Biol. 1993;122(1):113-21.
16. Zalokar M, Erk I. Division and migration of nuclei during early embryogenesis of Drosophila melanogaster. J Microscopie Biol Cell. 1976:25:97-106.

17. Warn RM, Magrath R, Webb S. Distribution of F-actin during cleavage of the Drosophila syncytial blastoderm. J Cell Biol. 1984;98(1):156-62.

18. Hatanaka K, Okada M. Retarded nuclear migration in Drosophila embryos with aberrant F-actin reorganization caused by maternal mutations and by cytochalasin treatment. Development. 1991;111(4):909-20.

19. Mavrakis M, Rikhy R, Lilly M, Lippincott-Schwartz J. Fluorescence imaging techniques for studying Drosophila embryo development. Curr Protoc Cell Biol. 2008:4:4-18.

20. Efimov A, Kharitonov A, Efimova N, Loncarek J, Miller PM, Andreyeva N, Gleeson P, Galjart N, Maia AR, McLeod IX, et al. Asymmetric CLASPdependent nucleation of noncentrosomal microtubules at the transGolgi network. Dev Cell. 2007;12(6):917-30.

21. Cai X, Fahmy K, Baumgartner S. bicoid RNA localization requires the transGolgi network. Hereditas. 2019;156:30.

22. Frescas D, Mavrakis M, Lorenz H, Delotto R, Lippincott-Schwartz J. The secretory membrane system in the Drosophila syncytial blastoderm embryo exists as functionally compartmentalized units around individual nuclei. J Cell Biol. 2006;173(2):219-30.

23. Ripoche J, Link B, Yucel JK, Tokuyasu K, Malhotra V. Location of Golgi membranes with reference to dividing nuclei in syncytial Drosophila embryos. Proc Natl Acad Sci U S A. 1994;91(5):1878-82.

24. Lattao R, Rangone H, Llamazares S, Glover DM. Mauve/LYST limits fusion of lysosome-related organelles and promotes centrosomal recruitment of microtubule nucleating proteins. Dev Cell. 2021;56(7):1000-1013e1006.

25. Ferrandon D, Elphick L, Nüsslein-Volhard C, St Johnston D. Staufen protein associates with the $3^{\prime} U T R$ of bicoid mRNA to form particles that move in a microtubule-dependent manner. Cell. 1994;79(7):1221-32.

26. Cui J, Sartain CV, Pleiss JA, Wolfner MF. Cytoplasmic polyadenylation is a major mRNA regulator during oogenesis and egg activation in Drosophila. Dev Biol. 2013;383(1):121-31.

27. Lazzaretti D, Veith K, Kramer K, Basquin C, Urlaub H, Irion U, Bono F. The bicoid mRNA localization factor Exuperantia is an RNA-binding pseudonuclease. Nat Struct Mol Biol. 2016;23(8):705-13.

28. Weidmann CA, Qiu C, Arvola RM, Lou TF, Killingsworth J, Campbell ZT, Tanaka Hall TM, Goldstrohm AC. Drosophila Nanos acts as a molecular clamp that modulates the RNA-binding and repression activities of Pumilio. Elife. 2016;5:1

29. Irion U, St Johnston D. bicoid RNA localization requires specific binding of an endosomal sorting complex. Nature. 2007;445(7127):554-8.

30. Goldman CH, Neiswender H, Veeranan-Karmegam R, Gonsalvez GB. The Egalitarian binding partners Dynein light chain and Bicaudal-D act sequentially to link mRNA to the Dynein motor. Development. 2019;146:15

31. Wagner C, Ehresmann C, Ehresmann B, Brunel C. Mechanism of dimerization of bicoid mRNA: initiation and stabilization. J Biol Chem. 2004;279(6):4560-9.

32. Surdej P, Jacobs-Lorena M. Developmental regulation of bicoid mRNA stability is mediated by the first 43 nucleotides of the 3 ' untranslated region. Mol Cell Biol. 1998;18(5):2892-900.

33. Salles FJ, Lieberfarb ME, Wreden C, Gergen JP, Strickland S. Coordinate initiation of Drosophila development by regulated polyadenylation of maternal messenger RNAs. Science. 1994;266(5193):1996-9.

34. Eichhorn SW, Subtelny AO, Kronja I, Kwasnieski JC, Orr-Weaver TL, Bartel DP. mRNA poly(A)-tail changes specified by deadenylation broadly reshape translation in Drosophila oocytes and early embryos. Elife. 2016:5:1.

35. Dubnau J, Struhl G. RNA recognition and translational regulation by a homeodomain protein. Nature. 1996;379(6567):694-9.

36. Rivera-Pomar R, Jackle H. From gradients to stripes in Drosophila embryogenesis: filling in the gaps. Trends Genet. 1996;12(11):478-83.

37. Papatsenko D, Goltsev Y, Levine M. Organization of developmental enhancers in the Drosophila embryo. Nucleic Acids Res. 2009;37(17):5665-77.

38. Jaeger J. The gap gene network. Cell Mol Life Sci. 2011;68(2):243-74.

39. Shokri L, Inukai S, Hafner A, Weinand K, Hens K, Vedenko A, Gisselbrecht SS, Dainese R, Bischof J, Furger E, et al. A Comprehensive Drosophila melanogaster Transcription Factor Interactome. Cell Rep. 2019;27(3):955970.e957. 
40. Lucchetta EM, Vincent ME, Ismagilov RF. A precise Bicoid gradient is nonessential during cycles 11-13 for precise patterning in the Drosophila blastoderm. PLoS One. 2008;3(11):e3651.

41. Juge F, Zaessinger S, Temme C, Wahle E, Simonelig M. Control of poly(A) polymerase level is essential to cytoplasmic polyadenylation and early development in Drosophila. Embo J. 2002;21(23):6603-13.

42. Brent AE, MacQueen A, Hazelrigg T. The Drosophila wispy gene is required for RNA localization and other microtubule-based events of meiosis and early embryogenesis. Genetics. 2000;154(4):1649-62.

43. Benoit P, Papin C, Kwak JE, Wickens M, Simonelig M. PAP- and GLD2-type poly $(A)$ polymerases are required sequentially in cytoplasmic polyadenylation and oogenesis in Drosophila. Development. 2008;135(11):1969-79.

44. Wang L, Eckmann CR, Kadyk LC, Wickens M, Kimble J. A regulatory cytoplasmic poly(A) polymerase in Caenorhabditis elegans. Nature. 2002;419(6904):312-6.

45. Kwak JE, Wang L, Ballantyne S, Kimble J, Wickens M. Mammalian GLD-2 homologs are poly(A) polymerases. Proc Natl Acad Sci U S A. 2004;101(13):4407-12.

46. Kwak JE, Wickens M. A family of poly(U) polymerases. RNA. 2007;13(6):860-7.

47. Cui J, Sackton KL, Horner VL, Kumar KE, Wolfner MF. Wispy, the Drosophila homolog of GLD-2, is required during oogenesis and egg activation. Genetics. 2008;178(4):2017-29.

48. Castillejo-Lopez C, Cai X, Fahmy K, Baumgartner S. Drosophila exoribonuclease nibbler is a tumor suppressor, acts within the RNA(i) machinery and is not enriched in the nuage during early oogenesis. Hereditas. 2017;155:1.

49. Walldorf U, Gehring WJ. Empty spiracles, a gap gene containing a homeobox involved in Drosophila head development. EMBO J. 1992;11(6):2247-59.

50. Stanojevic D, Small S, Levine M. Regulation of a segmentation stripe by overlapping activators and repressors in the Drosophila embryo. Science. 1991;254(5036):1385-7.

51. Small S, Blair A, Levine M. Regulation of even-skipped stripe 2 in the Drosophila embryo. EMBO J. 1992;11(11):4047-57.

52. Houchmandzadeh B, Wieschaus E, Leibler S. Establishment of developmental precision and proportions in the early Drosophila embryo. Nature. 2002;415(6873):798-802.

53. Martinez-Arias A, Lawrence PA. Parasegments and compartments in the Drosophila embryo. Nature. 1985;313(6004):639-42.

54. Combs PA, Eisen MB. Sequencing mRNA from cryo-sliced Drosophila embryos to determine genome-wide spatial patterns of gene expression. PloS one. 2013;8(8):e71820.

55. Janssens H, Hou S, Jaeger J, Kim AR, Myasnikova E, Sharp D, Reinitz J. Quantitative and predictive model of transcriptional control of the Drosophila melanogaster even skipped gene. Nat Genet. 2006;38(10):1159-65.

56. Gans M, Audit C, Masson M. Isolation and characterization of sexlinked female-sterile mutants in Drosophila melanogaster. Genetics. 1975;81(4):683-704

57. Zalokar M, Audit C, Erk I. Developmental defects of female-sterile mutants of Drosophila melanogaster. Dev Biol. 1975;47(2):419-32.

58. Loppin B, Berger F, Couble P. Paternal chromosome incorporation into the zygote nucleus is controlled by maternal haploid in Drosophila. Dev Biol. 2001;231(2):383-96.

59. Tang X, Cao J, Zhang L, Huang Y, Zhang Q, Rong YS. Maternal Haploid, a Metalloprotease Enriched at the Largest Satellite Repeat and Essential for Genome Integrity in Drosophila Embryos. Genetics. 2017;206(4):1829-39.

60. Delabaere L, Orsi GA, Sapey-Triomphe L, Horard B, Couble P, Loppin B. The Spartan ortholog maternal haploid is required for paternal chromosome integrity in the Drosophila zygote. Curr Biol. 2014;24(19):2281-7.

61. Lehner CF, O'Farrell PH. The roles of Drosophila cyclins A and B in mitotic control. Cell. 1990;61(3):535-47.

62. Stiffler LA, Ji JY, Trautmann S, Trusty C, Schubiger G. Cyclin A and B functions in the early Drosophila embryo. Development. 1999;126(23):5505-13

63. Ji JY, Haghnia M, Trusty C, Goldstein LS, Schubiger G. A genetic screen for suppressors and enhancers of the Drosophila cdk1-cyclin B identifies maternal factors that regulate microtubule and microfilament stability. Genetics. 2002;162(3):1179-95.
64. Aaboud M, Aad G, Abbott B, Abdallah J, Abdinov O, Abeloos B, Aben R, AbouZeid OS, Abraham NL, Abramowicz H, et al. Measurement of the Inelastic Proton-Proton Cross Section at sqrt $[\mathrm{s}]=13 \mathrm{TeV}$ with the ATLAS Detector at the LHC. Phys Rev Lett. 2016;117(18):182002.

65. Ali-Murthy Z, Kornberg TB. Bicoid gradient formation and function in the Drosophila pre-syncytial blastoderm. Elife. 2016;5:1.

66. Gottlieb E. The 3' untranslated region of localized maternal messages contains a conserved motif involved in mRNA localization. Proc Natl Acad Sci U S A. 1992;89(15):7164-8.

67. Vinter DJ, Hoppe C, Minchington TG, Sutcliffe C, Ashe HL. Dynamics of hunchback translation in real time and at single mRNA resolution in the Drosophila embryo. Development. 2021;148:dev196121.

68. Reza A, Yuan YG. microRNAs Mediated Regulation of the Ribosomal Proteins and its Consequences on the Global Translation of Proteins. Cells. 2021;10:1.

69. Larkin A, Marygold SJ, Antonazzo G, Attrill H, Dos Santos G, Garapati PV, Goodman JL, Gramates LS, Millburn G, Strelets VB, et al. FlyBase: updates to the Drosophila melanogaster knowledge base. Nucleic Acids Res. 2021:49(D1):D899-907.

70. McLaughlin JM, Smith DFQ, Catrina IE, Patru DP: P-bodies and the miRNA pathway regulate translational repression of bicoid mRNA during Drosophila melanogaster oogenesis. bioRxiv 2018.

71. Driever W, Nüsslein-Volhard C. The bicoid protein determines position in the Drosophila embryo in a concentration-dependent manner. Cell. 1988;54(1):95-104.

72. Gregor T, Tank DW, Wieschaus EF, Bialek W. Probing the limits to positional information. Cell. 2007;130(1):153-64.

73. Gregor T, McGregor AP, Wieschaus EF. Shape and function of the Bicoid morphogen gradient in dipteran species with different sized embryos. Dev Biol. 2008;316(2):350-8.

74. Little SC, Wieschaus EF. Shifting patterns: merging molecules, morphogens, motility, and methodology. Dev Cell. 2011;21(1):2-4.

75. Durrieu L, Kirrmaier D, Schneidt T, Kats I, Raghavan S, Hufnagel L, Saunders TE, Knop M. Bicoid gradient formation mechanism and dynamics revealed by protein lifetime analysis. Mol Syst Biol. 2018;14(9):e8355.

76. Huang A, Amourda C, Zhang S, Tolwinski NS, Saunders TE. Decoding temporal interpretation of the morphogen Bicoid in the early Drosophila embryo. Elife. 2017;6:e26258.

77. Liu F, Morrison AH, Gregor T. Dynamic interpretation of maternal inputs by the Drosophila segmentation gene network. Proc Natl Acad Sci U S A. 2013;110(17):6724-9.

78. Drocco JA, Wieschaus EF, Tank DW. The synthesis-diffusion-degradation model explains Bicoid gradient formation in unfertilized eggs. Phys Biol. 2012;9(5):055004

79. Drocco JA, Grimm O, Tank DW, Wieschaus E. Measurement and perturbation of morphogen lifetime: effects on gradient shape. Biophys J. 2011;101(8):1807-15.

80. Grimm O, Wieschaus E. The Bicoid gradient is shaped independently of nuclei. Development. 2010;137(17):2857-62.

81. Abu-Arish A, Porcher A, Czerwonka A, Dostatni N, Fradin C. High mobility of bicoid captured by fluorescence correlation spectroscopy: implication for the rapid establishment of its gradient. Biophys J. 2010;99(4):L33-35.

82. Namba R, Pazdera TM, Cerrone RL, Minden JS. Drosophila embryonic pattern repair: how embryos respond to bicoid dosage alteration. Development. 1997;124(7):1393-403.

83. Gregor T, Bialek W. de Ruyter van Steveninck RR, Tank DW, Wieschaus EF: Diffusion and scaling during early embryonic pattern formation. Proc Nat Acad Sci U S A. 2005;102(51):18403-7.

84. Foe VE, Odell GM, Edgar BA. Mitosis and morphogenesis in the Drosophila embryo: point and counterpoint. The Development of Drosophila melanogaster Ed by Bate M and Martinez Arias A Cold Spring Harbor Laboratory Press. 1993;1:149-300.

85. Jacobs HW, Knoblich JA, Lehner CF. Drosophila Cyclin B3 is required for female fertility and is dispensable for mitosis like Cyclin B. Genes Dev. 1998;12(23):3741-51.

86. Rosset A, Spadola L, Ratib O. OsiriX: an open-source software for navigating in multidimensional DICOM images. J Digit Imaging. 2004;17(3):205-16.

\section{Publisher's Note}

Springer Nature remains neutral with regard to jurisdictional claims in published maps and institutional affiliations. 